\title{
THE USE OF A SEQUESTRENE-CITRATE MIXTURE IN THE ESTIMATION OF THE BLOOD SEDIMENTATION RATE
}

\author{
BY \\ IAN D. MELVILLE AND BASIL M. RIFKIND \\ From the Royal Infirmary, Glasgow
}

(RECEIVED FOR PUBLICATION AUGUST 12, 1958)

\begin{abstract}
Many methods have been designed for estimating the erythrocyte sedimentation rate (E.S.R.), but the method of Westergren (1921) seems now to be the most widely used (Dacie, 1956). It has been preferred by several workers (Davis, 1946; Gilmour and Sykes, 1951; Goldberg and Conway, 1952 ; Goldberg, Glynn, and Bywaters, 1952) because it was felt to reflect the changes due to disease more accurately than the other methods, notably that of Wintrobe and Landsberg (1935). This preference has been endorsed recently by Galbraith and Jones (1958), who showed that high sedimentation rates could be found with the Westergren technique when the Wintrobe E.S.R. was normal or only slightly
\end{abstract} raised.

The only practical difficulty in estimating the E.S.R. has so far been the need to set up the sedimentation tubes within a fairly short time of withdrawing the blood. Many workers have observed that allowing the blood to stand, even for a few hours, is attended by progressive retardation of the rate of sedimentation (Boerner and Flippin, 1935 ; Cooper, 1926 ; Dorfman and Brooks, 1937 ; Gilligan and Ernstene, 1934 ; Ham and Curtis, 1938). Nichols (1942) stated that the general consensus of opinion was that delay in measuring the sedimentation of a sample might cause retardation of the rate. The maximum amount of permissible delay reported was variable, from a "few" to " several" hours. Wintrobe, describing his own method in 1951, stated that the blood should be used within two hours of collection for the determination of the E.S.R. Hadley and Weiss (1955) noted that the E.S.R. of stored oxalated blood was obviously unreliable.

One exception to this general retardation of the E.S.R. was pointed out by Koster (1937), who observed in cases of carcinoma and lymphogranuloma that the E.S.R. after blood had been stored for 24 hours showed no change. This was confirmed by Feldman (1940).

Nichols (1942) suggested that the retarding effect of delay in setting up the blood for measuring the E.S.R. might bear some relationship to the kind of anticoagulant used, and also to the temperature at which the blood samples were kept.

\section{Present Investigation}

In view of Nichols' suggestion, it was decided to investigate the sedimentation rate of both fresh and stored blood, using a modified Westergren technique incorporating sequestrene as the anticoagulant. Sequestrene (the disodium salt of ethylenediamine tetra-acetic acid) was first described by Dyckerhoff, Marx, and Ludwig (1942). Its use in routine haematology was described by Proescher (1951), Hadley and Larson (1953), Schmidt, Hane, and Gomez (1953), Wittgenstein (1953), and Hadley and Weiss (1955). As an anticoagulant it is 10 times more powerful than sodium citrate, but its most notable feature is its capacity to preserve the blood elements for several days. Schmidt et al. considered that sequestrene was superior to both heparin and oxalate for routine work. It has the added advantage of being very cheap.

\section{Methods}

Comparison of E.S.R. of Fresh Blood Using Westergren and Modified Sequestrene-citrate Techniques.-Twenty-five samples of venous blood were withdrawn for study from 22 patients who were being treated or investigated in a medical unit of the Royal Infirmary, Glasgow. Four millilitres of each sample was added to $1 \mathrm{ml}$. of $3.8 \%$ sodium citrate solution in a graduated test tube (tube A), and $5 \mathrm{ml}$. was placed in a bijou bottle containing $5 \mathrm{mg}$. of dried sequestrene. As soon as possible after the withdrawal of the blood, and in no case later than two hours after venepuncture, the sequestrene blood was mixed 
by manual inversion and rotation for three minutes (except where stated this mixing method was used throughout this work) and $4 \mathrm{ml}$. of this blood was added to another test tube containing $1 \mathrm{ml}$. of the sodium citrate solution (tube B). The contents of tube A were then mixed, and a pair of Westergren E.S.R. tubes filled from it and set up in the E.S.R. rack. The same procedure was carried out with the contents of tube $B$. The four sedimentation rates were read by one of us after one hour.

The rack was at first fitted with two spirit levels to ensure that the E.S.R. tubes were vertical. Later this device was abandoned in favour of a simple plumb line hanging from the top bar of the rack.

Comparison of E.S.R. of Fresh Blood and of Blood Stored for 24 Hours Using Sequestrene-citrate Technique.-Twenty-five $10 \mathrm{ml}$. samples of venous blood were collected and added to bottles containing $10 \mathrm{mg}$. of dried sequestrene. After mixing, $4 \mathrm{ml}$. blood was taken from each sample and diluted with $1 \mathrm{ml}$. of $3.8 \%$ sodium citrate solution in a test tube. The contents of the test tube were mixed and two Westergren E.S.R. tubes filled from it and set up. The sedimentation rates were read after one hour.

The remainder of each original blood sample was stored in the refrigerator at temperatures varying between 5 and $10^{\circ} \mathrm{C}$. After about 24 hours the stored blood was mixed by rotation in a mechanical mixer (Matthews, 1951) for at least 10 minutes. Four millilitres was then added to $1 \mathrm{ml}$. of the sodium citrate solution, mixed, and replicate estimations of the E.S.R. carried out as above. The stored blood

\section{TABLE I}

E.S.R. OF FRESH BLOOD USING CLASSIC WESTERGREN AND MODIFIED SEQUESTRENE-CITRATE METHODS

\begin{tabular}{|c|c|c|c|c|c|c|c|}
\hline \multirow[t]{2}{*}{$\begin{array}{c}\text { Sample } \\
\text { No. }\end{array}$} & \multirow[t]{2}{*}{ Sex } & \multirow[t]{2}{*}{ Age } & \multirow[t]{2}{*}{ Diagnosis } & \multicolumn{2}{|c|}{$\begin{array}{c}\text { E.S.R. } \\
\text { Citrate } \\
\text { Only }\end{array}$} & \multicolumn{2}{|c|}{$\begin{array}{l}\text { E.S.R. } \\
\text { Sequestrene- } \\
\text { citrate }\end{array}$} \\
\hline & & & & mm. & mm. & $\mathbf{m m}$. & $\mathrm{mm}$. \\
\hline $\begin{array}{r}1 \\
2 \\
3 \\
4 \\
5 \\
6 \\
7 \\
8 \\
9 \\
10 \\
11 \\
12 \\
13 \\
14 \\
15 \\
16 \\
17 \\
18 \\
19 \\
20 \\
21 \\
22 \\
23 \\
24 \\
25\end{array}$ & $\begin{array}{l}\mathbf{M} \\
\mathbf{F} \\
\mathbf{F} \\
\mathbf{F} \\
\mathbf{F} \\
\mathbf{F} \\
\mathbf{M} \\
\mathbf{M} \\
\mathbf{F} \\
\mathbf{F} \\
\mathbf{F} \\
\mathbf{F} \\
\mathbf{M} \\
\mathbf{M} \\
\mathbf{M} \\
\mathbf{M} \\
\mathbf{F} \\
\mathbf{F} \\
\mathbf{F} \\
\mathbf{M} \\
\mathbf{M} \\
\mathbf{F} \\
\mathbf{F} \\
\mathbf{F} \\
\mathbf{F}\end{array}$ & $\begin{array}{l}38 \\
59 \\
51 \\
77 \\
24 \\
62 \\
55 \\
76 \\
61 \\
60 \\
29 \\
61 \\
62 \\
63 \\
68 \\
55 \\
24 \\
48 \\
61 \\
57 \\
47 \\
29 \\
61 \\
65 \\
74\end{array}$ & 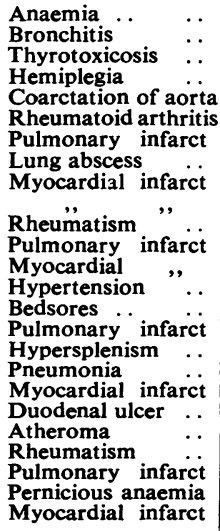 & $\begin{array}{c}3 \\
12 \\
6 \\
7 \\
6 \\
88 \cdot 5 \\
58 \\
101 \\
25 \\
10 \\
68 \\
40 \\
40 \\
2 \cdot 5 \\
105 \\
24 \\
4 \\
4 \\
13 \\
96 \\
6 \\
48 \\
39 \\
5 \cdot 5 \\
18\end{array}$ & $\begin{array}{c}2 \cdot 5 \\
11 \\
6 \\
7 \\
6 \\
83 \\
50 \\
98 \\
25 \\
10 \\
70 \\
43 \\
40 \\
4 \\
103 \\
26 \\
4 \\
4 \\
12 \cdot 5 \\
92 \\
7 \\
48 \\
40 \cdot 5 \\
5 \cdot 5 \\
18\end{array}$ & $\begin{array}{c}2 \cdot 5 \\
9 \cdot 5 \\
6 \\
7 \\
6 \\
95 \\
57 \\
99 \\
26 \\
10 \\
63 \\
51 \\
39 \\
4 \\
103 \\
27 \\
4 \\
4 \\
11 \\
97 \\
6 \\
46 \\
43 \\
5 \cdot 5 \\
20\end{array}$ & $\begin{array}{c}3 \\
12 \\
6 \\
8 \\
6 \\
96 \\
57 \\
96 \\
29 \\
10 \\
65 \\
48 \\
39 \\
4 \\
107 \\
24 \\
4 \\
4 \\
11 \cdot 5 \\
98 \\
7 \cdot 5 \\
47 \\
39 \\
5 \cdot 5 \\
18\end{array}$ \\
\hline \multicolumn{4}{|c|}{ Mean value of 25 estimations } & \multicolumn{2}{|c|}{$33 \cdot 18 \quad 32 \cdot 64$} & 33.66 & $33 \cdot 78$ \\
\hline ", & 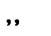 & , 50 & $\cdots$ & \multicolumn{2}{|c|}{32.91} & \multicolumn{2}{|c|}{$33 \cdot 72$} \\
\hline
\end{tabular}

should have reached room temperature by the time the dilution and mixing had been completed and temperature measurements were not made.

\section{Results}

The results of the experiments are shown in Tables I and II, which give the age, sex, and diagnosis of each case. Mean values for the E.S.R. are also shown.

\section{Discussion}

The results have been submitted to analysis of variance and this has shown that there is no significant difference between the mean values 32.91 and 33.72 in experiment 1 , or between the mean values 32.27 and 32.08 in experiment 2 .

With the classic Westergren technique in experiment 1 the maximum differences between duplicate sedimentation rates were $8 \mathrm{~mm}$. in sample No. 7 and $5.5 \mathrm{~mm}$. in sample No. 6 . In 20 of the 25 samples the difference between the duplicates was $2 \mathrm{~mm}$. or less. With the modified technique in experiment 1,18 of the samples showed a difference of $2 \mathrm{~mm}$. or less, five a difference of 2 to $3 \mathrm{~mm}$., and the greatest difference was of $4 \mathrm{~mm}$. in sample No. 15 (range 103-107 $\mathrm{mm}$.) and in sample No. 23 (range $39-43 \mathrm{~mm}$.).

The maximum discrepancy between pairs of sedimentation rates from the same patient was seen in sample No. 6 (difference of means 9.75 $\mathrm{mm}$. in a range of 83 to $96 \mathrm{~mm}$.). Nineteen samples showed a difference of means of $2 \mathrm{~mm}$. or less, and two a difference of means of 2 to $3 \mathrm{~mm}$.

The results were so closely comparable that we accepted that the sequestrene-citrate modification provided an accurate method of estimating the Westergren E.S.R.

From Table II it is seen that in 23 samples the difference between duplicate sedimentation rates of fresh sequestrene-citrate blood was $2 \mathrm{~mm}$. or less. The greatest difference was $4 \mathrm{~mm}$. in sample No. 42 (range of 58.5 to $62.5 \mathrm{~mm}$.). The duplicate estimations on the stored sequestrene blood showed no difference greater than $2 \mathrm{~mm}$. The maximum differences between means of sedimentation rates of fresh blood and stored blood are shown in Table III.

In 15 of the samples in experiment 2 the difference of the mean E.S.R. of fresh and stored blood was $2 \mathrm{~mm}$. or less, in four samples it lay between 2 and $3 \mathrm{~mm}$., and in one sample it was $4 \mathrm{~mm}$. Despite the close comparability of these 20 results, and despite the satisfactory analysis of variance, some further consideration must be given 
TABLE II

E.S.R. OF FRESH BLOOD AND OF BLOOD STORED FOR 24 HOURS USING SEQUESTRENE-CITRATE TECHNIQUE

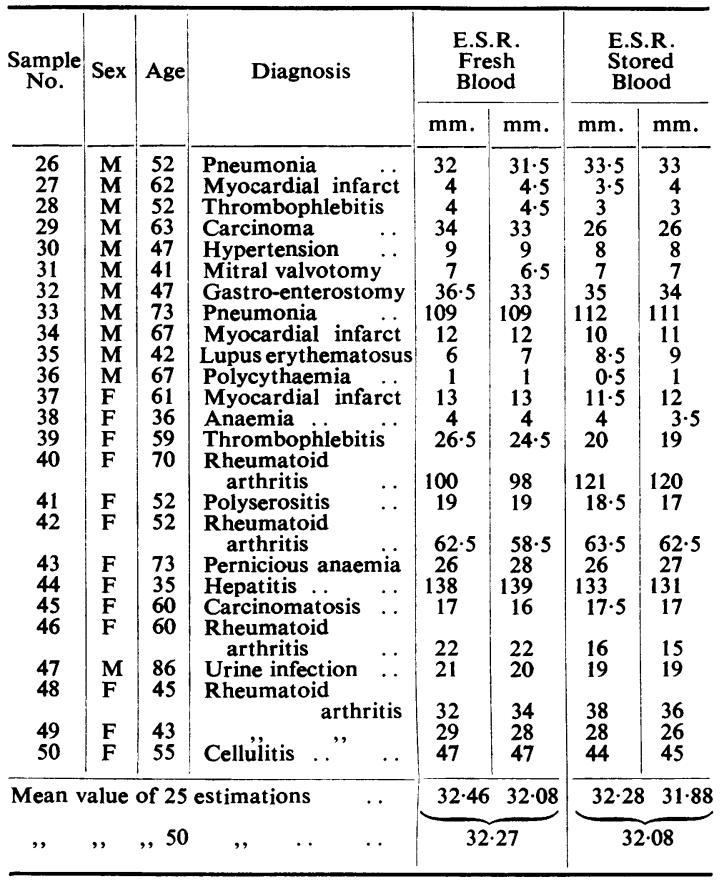

TABLE III

DIFFERENCES OF MEANS OF SEDIMENTATION RATES OF FRESH BLOOD AND OF BLOOD STORED FOR 24 HOURS

\begin{tabular}{c|c|c}
\hline $\begin{array}{c}\text { Sample } \\
\text { No. }\end{array}$ & $\begin{array}{c}\text { Difference of Means } \\
(\mathrm{mm} .)\end{array}$ & $\begin{array}{c}\text { Range of E.S.R. } \\
\text { (mm.) }\end{array}$ \\
\hline 40 & $21 \cdot 5$ & 98 to 121 \\
29 & $7 \cdot 5$ & $26,, 34$ \\
46 & $6 \cdot 5$ & $15,, 22$ \\
44 & $6 \cdot 5$ & 131,2139 \\
39 & 6.0 & $19,, 26.5$ \\
\hline
\end{tabular}

to the discrepancies listed in Table III. What clinical significance is to be attached to them ? If the E.S.R. of the fresh blood sample is taken as the "correct" E.S.R., it will be seen from Table II that storage of the blood was followed by acceleration of the sedimentation rate in sample 40 but by slight retardation in samples $29,46,44$, and 39. It is thought safe to disregard the retardation in sample No. 44 in which the rate fell from a mean value of 138.5 to a mean value of $132 \mathrm{~mm}$. In none of the other three cases of retardation has the E.S.R. change any clinical significance, whether the sedimentation test is used as a screening procedure or as an observation on the progress of a case. We think that our results compare favourably with those of Goldberg and Conway (1952), who modified the Westergren method by the addition of oxalated blood to $3.8 \%$ sodium citrate solution. They showed that, with the modified technique, the E.S.R. of oxalated blood was quite inaccurate after storage for 24 hours at room temperature.

There are only a few reports of the use of sequestrene in estimating the blood sedimentation rate, and these describe Wintrobe techniques or do not specify the E.S.R. technique used. A comparison was made by Hadley and Larson (1953) of the E.S.R. of blood, some of which had been treated with oxalate and the rest with sequestrene. They found no significant differences in 26 comparisons. Proescher (1951) had observed that if sequestrene blood was stored at $5^{\circ}$ C. the E.S.R. remained about the same for several days provided that the blood was re-mixed without excessive shaking. Hadley and Weiss (1955) stored sequestrene blood for 24 hours and noted that the E.S.R. was considerably less affected by the storage than was the E.S.R. of stored oxalated blood.

In the present investigation, with a modified Westergren technique, it has been shown that the storage of sequestrene blood for 24 hours at $5-10^{\circ}$ C. had no effect on the E.S.R. of 20 out of 25 samples. The storage was followed by a clinically insignificant slowing in four samples and by a moderate acceleration in the remaining one.

The introduction of the sequestrene-citrate method, therefore, obviates the need to dilute blood in sodium citrate at the bedside, as in the standard Westergren method, and the E.S.R. can be reliably estimated after a blood sample has been stored for 24 hours. The modified method would be of particular value in hospital outpatient departments, or possibly as part of a clinical laboratory service for general practitioners. It will be noted in passing that a complete blood examination, including an E.S.R., can be carried out on one sample of sequestrene blood.

\section{Summary}

The retardation of the E.S.R. which is seen when blood is stored is thought to be related to the anticoagulant used and to the temperature at $\mathrm{c}$ which it is stored. Sequestrene, a recently introduced anticoagulant, has been used in a study of 0

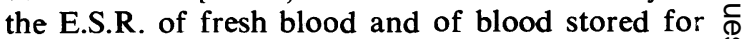

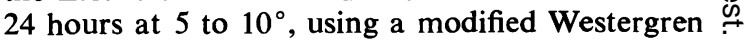
technique. The E.S.R. of blood treated with 7 sequestrene and then added to sodium citrate solution does not differ from the classic Westergren E.S.R. Storage of sequestrene blood as outlined above makes no appreciable difference to the E.S.R. using the modified technique. The 
introduction of the sequestrene-citrate method will extend the use of the sedimentation test in clinical practice.

We wish to thank Dr. R. A. Robb, of the Mathematics Department of Glasgow University, for the statistical analyses, and Dr. E. G. Oastler, of the Royal Infirmary, Glasgow, for advice and criticism.

\section{REFERENCES}

Boerner, F., and Flippin, H. F. (1935). J. Lab. clin. Med., 20, 583.

Cooper, H. N. (1926). Ibid., 11, 615.

Dacie, J. V. (1956). Practical Haematology, 2nd ed. J. \& A. Churchill, London.

Davis, L. J. (1946). Practitioner, 157, 13.

Dorfman, R. I., and Brooks, C. (1937). J. Lab. clin. Med., 22, 510.

Dyckerhoff, H., Marx, R., and Ludwig, B. (1942). Z. ges. exp. Med., 110,412 .

Feldman, H. (1940). Amer. J. med. Sci., 200, 820.
Galbraith, H.-J. B., and Jones, K. W. (1958). Brit. med. J., 1, 1144. Gilligan, D. R., and Ernstene, A. C. (1934). Amer. J. med. Sci., $187,552$.

Gilmour, D., and Sykes, A. J. (1951). Brit. med. J., 2, 1496.

Goldberg, A., and Conway, H. (1952). Ibid., 2, 315.

Goldberg, S., Glynn, L. E., and Bywaters, E. G. L. (1952). Ibid., $1,202$.

Hadley, C. G., and Larson, N. L. (1953). Amer. J. clin. Path., 23, 613.

— and Weiss, S. P. (1955). Ibid., 25, 1090.

Ham, T. H., and Curtis, F. C. (1938). Medicine (Baltimore), 17, 447.

Koster, L. (1937). Acta med. scand., 93, 420.

Matthews, G. A. (1951). J. clin. Path., 4, 383.

Nichols, R. E. (1942). J. Lab. clin. Med., 27, 1317.

Proescher, F. (1951). Proc. Soc. exp. Biol. (N.Y.), 76, 619.

Schmidt, C. H., Hane, M. E., and Gomez, D. C. (1953). U.S. armed Forces med. J., 4, 1556.

Westergren, A. (1921). Acta med. scand., 54, 247.

Wintrobe, M. M. (1951). Clinical Hematology, 3rd ed. Lea and Febiger, Philadelphia.

and Landsberg, J. W. (1935). Amer. J. med. Sci., 189, 102.

Wittgenstein, A. M. (1953). Amer. J. med. Technol., 19, 59. 